\title{
Patient centred diagnosis: sharing diagnostic decisions with patients in clinical practice
}

Shared decision making for diagnostic decisions is understudied and differs from treatment decision making. Zackary D Berger and colleagues discuss how uncertainty and stakes should shape the conversation

\section{Zackary D Berger associate professor of medicine ${ }^{1}$, Juan P Brito assistant professor of medicine ${ }^{2}$, Naykky Singh Ospina assistant professor of medicine ${ }^{3}$, Suraj Kannan medical student ${ }^{1}$, Jeremiah $S$ Hinson instructor of emergency medicine ${ }^{1}$, Erik $\mathrm{P}$ Hess professor of emergency medicine ${ }^{2}$, Helen Haskell president ${ }^{4}$, Victor M Montori professor of medicine ${ }^{2}$, David E Newman-Toker professor of neurology, ophthalmology, and otolaryngology ${ }^{1}$}

\footnotetext{
${ }^{1}$ Johns Hopkins University School of Medicine, Johns Hopkins Outpatient Center, 601 N Caroline St Suite 7143, Baltimore, MD 21287 US; ${ }^{2}$ Mayo Clinic, Rochester, MN, USA; ${ }^{3}$ Division of Endocrinology, University of Florida School of Medicine, Gainesville, FL, USA; ${ }^{4}$ Mothers Against Medical Error
}

In 2001, the National Academy of Medicine set out its vision to prioritise patient centred care: to ensure that clinical decisions "respect patients' wants, needs, and preferences and that patients have the education and support they need to make decisions and participate in their own care." ${ }^{1}$ Similar aims also exist in UK health strategy. ${ }^{2}$ Patient centred care is best delivered through patient-clinician relationships that foster shared decision making; an approach that has been shown to encourage health promoting behaviours, reduce inappropriate or unnecessary use of care, and improve patient and clinician satisfaction.-5

\section{Shared decision making and diagnosis}

Shared decision making goes beyond simple information exchange: it emphasises collaborative, often iterative, deliberation between patients, family, and clinicians, to advance the desired outcomes identified by the patient (fig $1 \Downarrow$ ). ${ }^{6-10}$

This deliberation should cover patient preferences that are global (such as the patient's capacity and desire to be involved in decision making) and specific (such as the patient's concerns, knowledge, and prior beliefs and preferences about specific diseases or tests). The clinician should seek to understand the patient in both the customary patient role and as a unique individual whose personhood extends beyond their illness. Table $1 \Downarrow$ shows the techniques that physicians can use to achieve the goals of patient centred care

Despite the well recognised burden of diagnostic error and rising use and cost of diagnostic tests, ${ }^{14-16}$ interventions to encourage shared decision making have largely focused on screening and treatment decisions. Meanwhile, the importance of shared decision making in diagnostic decisions has been relatively neglected.

Although the processes of diagnosis and treatment are not completely decoupled, shared decision making for diagnosis has distinct considerations (table $2 \Downarrow$ ). A key difference is the nature of the patient's concerns; treatment decisions assume an existing condition, whereas diagnostic situations require clarification of the condition; for example, "my child fell and hit his head, does he need a brain scan?" This difference is critical, because uncertainty is often much greater for diagnosis than treatment, making it much more challenging to explain the options and weigh the risks and benefits to the patient.

Managing the wide array of diagnostic possibilities for an undifferentiated symptom is also complicated by a patient's tolerance of uncertainty, how they as individuals manage trade-offs between false negative and false positive results, and how they act on test results. Precisely quantified benefits and harms are less likely to be available for diagnosis than treatment,${ }^{18}$ especially with respect to incidental or false positive results. This is sometimes referred to as the "cascade effect,"), in which initial, smaller scale decisions give rise to a chain of diagnostic procedures that might be unwarranted in hindsight. ${ }^{24}$ Additionally, a patient's values and preferences might be unstable, undefined, evolving, or difficult to express verbally or explicitly: patients may just have a "gut feeling" about a decision that is hard to articulate. ${ }^{25}$ As a result, decision making for diagnosis is often more iterative than for treatment, and may need to happen over an extended period of time. 


\section{Key messages}

Patient centred diagnosis is best practised through shared decision making; an iterative dialogue between doctor and patient, which respects a patient's needs, values, preferences, and circumstances

Shared decision making for diagnostic situations differs fundamentally from that for treatment decisions. This has important implications when considering its practical application

The nature of dialogue should be tailored to the specific diagnostic decision; scenarios with higher stakes or uncertainty usually require more detailed conversations

The nature, detail, and depth of the shared decision making process depends on the unique characteristics of the patient and the clinical context; uncertainty intolerable to a doctor might be tolerable to a patient, and a high stakes decision for one patient might be a moderate or low stakes decision for another.

Diagnostic uncertainty includes incomplete information (such as early manifestations or common, undifferentiated symptoms), limited evidence (including unknown diagnostic test sensitivity and specificity), or unclear impact of patient preferences on appropriate choice of diagnostic strategies for achieving the patients' health goals. Stakes refer to the potential impact of benefits or harms of diagnostic workups on outcomes that matter to patients.

Uncertainty and stakes should be viewed through meaningful conversation with the patient. How they should guide the intensity of conversations (fig $2 \Downarrow$; appendix) is explored below in a series of case studies.

\section{Case studies}

For routine diagnostic cases or, more broadly, when uncertainty and risks of testing are both low, clinicians should focus on conveying in a straightforward manner the value of the diagnostic procedure (box 1).

Clinicians should seek to obtain the patient's consent to proceed with testing but need not generally engage in deeper, more detailed shared decision making dialogue unless the patient hesitates, hedges, or declines (box 2).

If patient preferences for a particular test are known to be highly variable-such as genetic testing for untreatable diseases or procedures that might have high out-of-pocket costs for a patient-more extensive dialogue is appropriate, regardless of the certainty of benefits and harms of a work-up (box 3).

When knowledge of the benefits or harms of diagnostic evaluation is highly uncertain or moderately certain evidence favours neither choice, - a deeper, more detailed, and iterative shared decision making process becomes essential (box 4). In some scenarios, such as in emergency care, high stakes and high levels of uncertainty are coupled with time pressure. In these scenarios shared decision making faces unique challenges and assumes even greater importance (box 5).

\section{Conclusion and future research}

The cases above illustrate how evidence and values (from both patient and clinician) can interact to affect uncertainty, and provide clinical examples where detailed shared decision making is integral for achieving patient centred diagnosis. Centring diagnostic decision making around the patient has the potential to improve diagnostic safety and quality, ${ }^{29}$ and align diagnostic strategies with patient values and preferences. ${ }^{30}$ The growing science of patient reported outcomes may inform our understanding of how to best incorporate patient preferences explicitly into shared decision making for diagnosis. ${ }^{31}$ Recognition of the economic forces driving diagnostic testing — and a better understanding of how these could be integrated with a patient-centred approach — would help foster the routine use of shared decision making in diagnostic practice. $^{32}$

Contributors and sources: The authors have experience and research interests in patient-centred care, patient-clinician communication, diagnostic error, and shared decision making. We have explicitly included a patient advocate with experiences related to diagnostic error as one of our co-authors $(\mathrm{HH})$. The initial draft was prepared by ZDB, SK, and DENT. All authors provided substantive intellectual contributions, reviewed subsequent drafts and provided revisions, and collaborated on and approved the final draft. JH and EPH contributed to case study development. ZDB is the guarantor for the manuscript.

Competing interests: We have read and understood BMJ policy on declaration of interests and declare that DENT was supported by the Armstrong Institute Center for Diagnostic Excellence at Johns Hopkins University School of Medicine. SK is supported by an NIH Medical Scientist Training Program grant.

Provenance and peer review: Not commissioned; externally peer reviewed.

1 Envisioning the National Health Care Quality Report. Published Online First: 2001. https: //www.nap.edu/catalog/10073/envisioning-the-national-health-care-quality-report

2 Department of Health. Equity and excellence: liberating the NHS. 2010. www.dh.gov.uk

3 Dontje K, Corser W, Kreulen G, Teitelman A. A unique set of interactions: the MSU Dontje K, Corser W, Kreulen G, Teitelman A. A unique set of interactions: the MSU
sustained partnership model of nurse practitioner primary care. J Am Acad Nurse Pract 2004;359:63-9. doi:10.1111/j.1745-7599.2004.tb00374.x pmid:15055423.

4 Robinson JH, Callister LC, Berry JA, Dearing KA. Patient-centered care and adherence: definitions and applications to improve outcomes. J Am Acad Nurse Pract 2008;359:600-7. doi:10.1111/1.1745-7599.2008.00360.x pmid:19120591.

5 Stewart M, Brown JB, Donner A, et al. The impact of patient-centered care on outcomes. J Fam Pract 2000;359:796-804.http://www.ncbi.nlm.nih.gov/entrez/query.fcgi? $\mathrm{cmd}=$ Retrieve\&db=PubMed\&list_uids=11032203\&dopt=Abstract

6 Hargraves I, LeBlanc A, Shah ND, Montori VM. Shared Decision Making: The Need For Patient-Clinician Conversation, Not Just Information. Health Aff (Millwood) 2016;359:627-9. doi:10.1377/hlthaff.2015.1354 pmid:27044962.

7 Elwyn G, Dehlendorf C, Epstein RM, Marrin K, White J, Frosch DL. Shared decision making and motivational interviewing: achieving patient-centered care across the spectrum of health care problems. Ann Fam Med 2014;359:270-5. doi:10.1370/afm.1615 pmid: 24821899.

8 Elwyn G, Frosch D, Thomson R, et al. Shared decision making: a model for clinical practice. J Gen Intern Med 2012;359:1361-7. doi:10.1007/s11606-012-2077-6 pmid: 22618581.

9 Makoul G, Clayman ML. An integrative model of shared decision making in medical encounters. Patient Educ Couns 2006;359:301-12. doi:10.1016/j.pec.2005.06.010 pmid: 16051459.

10 Cohen MD. Engaging patients in understanding and using evidence to inform shared decision making. Patient Educ Couns 2017;359:2-3. doi:10.1016/..pec.2016.11.013 pmid: 27986242.

11 Epstein RM, Street RL. Patient-centered communication in cancer care: Promoting healing and reducing suffering. https://healthcaredelivery.cancer.gov/pcc/pcc_monograph.pdf

12 Levinson W, Lesser CS, Epstein RM. Developing physician communication skills for patient-centered care. Health Aff (Millwood) 2010;359:1310-8. doi:10.1377/hlthaff.2009. 0450 pmid:20606179.

13 King A, Hoppe RB. "Best practice" for patient-centered communication: a narrative review. $J$ Grad Med Educ 2013;359:385-93. doi:10.4300/JGME-D-13-00072.1 pmid:24404300.

14 McGlynn EA, McDonald KM, Cassel CK. Measurement is essential for improving diagnosis and reducing diagnostic error: a report from the Institute of Medicine. JAMA 2015;359:2501-2. doi:10.1001/jama.2015.13453 pmid:26571126.

15 Redberg R, Katz M, Grady D. Diagnostic tests: another frontier for less is more: or why talking to your patient is a safe and effective method of reassurance. Arch Intern Med 2011;359:619. doi:10.1001/archinternmed.2010.465 pmid:21149744.

16 McCaffery KJ, Jansen J, Scherer LD, et al. Walking the tightrope: communicating overdiagnosis in modern healthcare. BMJ 2016;359:i348. doi:10.1136/bmj.i348 pmid: 26850726.

17 Manski CF. Diagnostic testing and treatment under ambiguity: using decision analysis to inform clinical practice. Proc Natl Acad Sci U S A 2013;359:2064-9. doi:10.1073/pnas. 1221405110 pmid:23341625.

18 Schünemann HJ, Oxman AD, Brozek J, et al. GRADE Working Group. Grading quality of evidence and strength of recommendations for diagnostic tests and strategies. $B M J$ 2008;359:1106-10. doi:10.1136/bmj.39500.677199.AE pmid:18483053. 


\section{Box 1: Temporal headache}

A 75 year old man who lives independently and whose only medical problem is mild osteoarthritis is seen in primary care with bitemporal headaches and jaw claudication. The clinician suspects giant cell arteritis and plans to order an erythrocyte sedimentation rate test. She explains her diagnostic suspicion to the patient in plain language and her rationale for ordering the test. She offers the patient the opportunity to provide further input or ask any questions he or his family might have.

\section{Discussion}

Extensive shared decision making has no substantial role here, for several reasons. Firstly, the patient's symptoms are highly indicative of a dangerous disorder that can cause major harm (blindness). Secondly, the disease is treatable, and there is general consensus that the benefits of treatment outweigh the harms. Thirdly, the test (venepuncture) contributes to the diagnosis, is low cost, and is nearly free of risk. Lastly, not ordering the test is considered medically negligent. The contextual features of this encounter make it highly improbable that any patient's values and preferences (however extreme) would over-ride the strong rationale for ordering the test. Effective communication between patient and physician is still important, but the shared decision making conversation need not be conducted in great depth or detail.

\section{Box 2: Low back pain}

A 53 year old man presents with a one week history of low back pain after lifting heavy furniture. After taking a history and physically examining the patient, the clinician finds no abnormal neurological signs. She recommends that the patient apply heat, sleep comfortably, and take over the counter analgesics as needed. The patient expresses worry and is uncomfortable that no further tests are performed. He requests magnetic resonance imaging (MRI) of the back "just to be sure that nothing is wrong." Using best available evidence, the clinician uses patient centred care techniques (table $1 \downarrow$ ) to discourage testing, explaining that the image is more likely to give false positive findings than to identify an important medical problem. The patient is visibly distressed and anxious and stops talking. The clinician invites the patient to express his concerns and fears; he discloses that his sibling was recently diagnosed as having renal cancer, which first manifested with lower back pain.

\section{Discussion}

The general medical consensus is that, in the absence of neurological abnormalities, computed tomography and MRI are unnecessary for lower back pain and potentially harmful, given the small risks inherent with imaging plus the potential harms of downstream treatment for incidental findings. The patient expressed a strong and repeated desire for further diagnostic testing, which might be based on values, knowledge, or past experiences that the clinician has not fully explored. The clinician should use shared decision making techniques (table $1 \Downarrow$ ) to ensure that she is fully aware of what the patient understands about the nature of his pain, about the benefits and risks of imaging, and the patient's underlying fears. This does not imply that diagnostic testing should be pursued-the end result of shared decision making must be to avoid imaging that is not medically indicated. The aim is to further the conversation and make a decision based on a deeper exploration of the patient's concerns. Although the clinician should discourage imaging procedures that are not based on evidence, the decision should reflect the specific preferences and needs of this unique patient. ${ }^{26}$ Learning about the recent diagnosis of renal cancer in a sibling might lead to an entirely different, jointly developed diagnostic plan, such as urinalysis and imaging of the kidneys if the urinalysis shows evidence of microscopic haematuria.

\section{Box 3: Family history of Huntington's disease}

At a routine visit, a 25 year old woman tells her GP that her father was recently diagnosed as having Huntington's disease after showing neurological symptoms. She says that she is hesitant to get screened for the disease because she is scared of what will happen to her life if she finds out that she carries the gene defects.

\section{Discussion}

Screening for genetic diseases such as Huntington's disease is controversial and complicated. Patients might choose to avoid learning their genetic status because of how the knowledge might affect their daily life; they might fear social stigma or experience personal frustration with an untreatable, inevitable health condition. The patient may be concerned that their knowledge of a future onset of a devastating disease might affect their employment or insurance. Evidence links the diagnosis with an increased risk of suicide. Some patients may decide not to have children. The clinician should recognise that these complex concerns, values and preferences may change, perhaps under different life circumstances, and should therefore be ready to modify the diagnostic plan accordingly.

19 Crossing the Quality Chasm. http//www.nationalacademies.org/hmd/ /media/Files/ Report\%20Files/2001/Crossing-the-Quality-Chasm/Quality\%20Chasm\%202001\%20\% 20report\%20brief.pdf

20 Welch HG, Black WC. Overdiagnosis in cancer. J Natl Cancer Inst 2010;359:605-13. doi: 10.1093/jnci/djq099 pmid:20413742.

21 Saber Tehrani AS, Lee H, Mathews SC, et al. 25-Year summary of US malpractice claims for diagnostic errors 1986-2010: an analysis from the National Practitioner Data Bank. BMJ Qual Saf 2013;359:672-80. doi:10.1136/bmjqs-2012-001550 pmid:23610443.

22 Feinstein AR. The 'chagrin factor' and qualitative decision analysis. Arch Intern Med 1985;359:1257-9. doi:10.1001/archinte.1985.00360070137023 pmid:4015276.

23 Polaris JJ, Katz JN. "Appropriate" diagnostic testing: supporting diagnostics with evidence-based medicine and shared decision making. BMC Res Notes 2014;359:922. doi:10.1186/1756-0500-7-922 pmid:25515327.

24 The cascade effect in the clinical care of patients. N Engl J Med 1986;359:319-20. doi: 10.1056/NEJM198607313150511 pmid:3724824

25 Epstein RM, Street RL Jr. Shared mind: communication, decision making, and autonomy in serious illness. Ann Fam Med 2011;359:454-61. doi:10.1370/afm.1301 pmid:21911765.

26 Solomon MZ, Gusmano MK, Maschke KJ. The ethical imperative and moral challenges of engaging patients and the public with evidence. Health Aff (Millwood) 2016;359:583-9. doi:10.1377/hlthaff.2015.1392 pmid:27044955.
27 Brach C. They said my dad was having a stroke. I wish I had been able to handle it better Washington Post 2016.http://www.highbeam.com/doc/1p2-39618408.html?refid=easy_ hf.

28 Flynn D, Nesbitt DJ, Ford GA, et al. Development of a computerised decision aid for thrombolysis in acute stroke care. BMC Med Inform Decis Mak 2015;359:6. doi:10.1186/ s12911-014-0127-1 pmid:25889696.

29 Singh H, Naik AD, Rao R, Petersen LA. Reducing diagnostic errors through effective communication: harnessing the power of information technology. $J$ Gen Intern Med 2008;359:489-94. doi:10.1007/s11606-007-0393-z pmid:18373151.

30 Mulley AG, Trimble C, Elwyn G. Stop the silent misdiagnosis: patients' preferences matter BMJ 2012;359:e6572. doi:10.1136/bmj.e6572 pmid:23137819.

31 Lavallee DC, Chenok KE, Love RM, et al. Incorporating Patient-Reported Outcomes Into Health Care To Engage Patients And Enhance Care. Health Aff (Millwood) 2016;359:575-82. doi:10.1377/hlthaff.2015.1362 pmid:27044954.

32 Newman-Toker DE, McDonald KM, Meltzer DO. How much diagnostic safety can we afford, and how should we decide? A health economics perspective. BMJ Qual Saf 2013;359(Suppl 2):ii11-20. doi:10.1136/bmjqs-2012-001616 pmid:24048914.

Published by the BMJ Publishing Group Limited. For permission to use (where not already granted under a licence) please go to http://group.bmj.com/group/rights-licensing/ permissions 


\section{Box 4: Thunderclap headache}

A 27 year old woman presents to the emergency department with an intense, throbbing headache for the past 24 hours. She does not remember exactly how it started but notes that it built to maximum intensity within minutes. She has had headaches seven or eight times in the past year and has been diagnosed with migraines. These previous episodes have lasted up to 12 hours, and she is usually able to manage the symptoms with over the counter ibuprofen and resting in a quiet, dark room until the pain subsides. This time, however, the pain was more rapid in onset and more intense than any headache she can remember. The pain is not relieved by drug treatment. She has vomited twice since the episode began, which has never happened before. She has had no recent trauma that she can recall. A careful physical examination shows no focal neurological abnormalities. She is taken for immediate computed tomography (CT), which shows no evidence of subarachnoid haemorrhage or other intracranial pathology. She is observed in a quiet, unlit room and given intravenous fluids, a dopamine receptor antagonist, and a non-steroidal anti-inflammatory drug. The patient reports feeling better in several hours and meets with the attending physician to discuss the appropriate next steps.

At this encounter, the doctor seeks to build rapport with the patient. The patient notes that her migraines have forced her to consult regularly with neurologists and says that she is tired of repeated diagnostic tests that don't relieve her pain. The doctor acknowledges her frustration and explains that the gold standard diagnostic approach for an intense sudden onset headache with negative CT results is a lumbar puncture. $\mathrm{He}$ also says that, although the diagnostic value of lumbar puncture after negative CT is debated in this clinical context, his personal tendency with previous patients has been to pursue further testing. Given the high stakes of the diagnostic situation, and high uncertainty, the patient and doctor develop and agree on a diagnostic plan. They discuss the data on how accurately clinical features and CT scans detect subarachnoid haemorrhage and consider several diagnostic options, including lumbar puncture, other imaging (such as CT angiography or MRI with angiography), and watchful waiting. After thoroughly discussing the potential benefit and consequences of each approach, the patient and doctor agree to pursue watchful waiting to reduce the burden of additional diagnostic testing on the patient. She is then discharged after migraine management counselling.

The patient presents three months later for follow-up with her GP. She reports that she has continued to have migraine episodes, at greater frequency than before the recent acute event, though none had the intensity that brought her to the emergency department-these are reasonably well controlled with medication. She tells the GP that she read online that recurrent headaches might be symptomatic of brain tumours and asks if she should be concerned. She denies any weight loss, constitutional symptoms, vision changes, seizures, or other neurological symptoms. The GP agrees that a CT scan might have missed a small intracranial tumour that could potentially be detected by other means, such as MRI. He also explains the possibility for MRI to pick up incidental findings that could lead to unnecessary treatment. He recommends forgoing MRI for now with a plan to revisit if the patient presents with new neurological symptoms. The patient is fine with this plan and thanks the physician for answering her question. They agree to follow-up every three months or if any new symptoms arise.

\section{Discussion}

Even though migraines are the most likely diagnosis in this case, brain aneurysms and brain tumours are most common among dangerous mimics. Worsening or ongoing headaches may bring rare, dangerous disorders into consideration, such as dural arteriovenous malformation (requiring catheter angiography for diagnosis) or isolated central nervous system vasculitis (for which no test or combination of diagnostic tests, including neuroimaging, lumbar puncture, conventional angiography, and brain biopsy, is definitive).

Problems like this are difficult to formulate, even for the clinician, and are even more challenging to discuss with the patient. Even if the diagnostic quandary is artificially constrained to reflect only the differential diagnosis of migraine versus aneurysm, there may be patient specific diagnostic parameters for which no evidence exists. What is the likelihood of aneurysmal subarachnoid haemorrhage in a patient with previous migraine, new thunderclap type, worst ever headache, first ever vomiting, with negative CT at 24 hours, no lumbar puncture result, responsive to treatment, but then increased frequency (but not severity) of headaches without new neurological symptoms? Patients with previous migraine were excluded from critical studies establishing clinical prediction rules for aneurysms in patients with acute headache. Each patient's story has nuances that might be pertinent (eg, greater frequency but not severity afterwards) but cannot readily be translated into firm, probabilistic estimates.

With multiple possible diagnoses and next steps, the overall decision tree becomes complex and uncertain. After deciding to pursue tests rather than watchful waiting, the doctor and patient must decide the sequence of tests and any stopping rules; for example, whether to do MRI plus magnetic resonance angiography first and stop if the results are negative; go straight to catheter angiography, which has the highest likelihood of ruling out all of the relevant dangerous disorders but has non-trivial risks; or do a lumbar puncture, which is less risky and might distinguish xanthochromia from chronic bleeding or raised protein from low grade inflammation associated with vasculitis but is insensitive and not definitive for any of the diagnoses in question.

The situation is further complicated by the differing psychology of decision making between doctor and patient. Clinicians might advocate a risk averse approach to minimise harm through diagnostic error, whereas patients might want to avoid burdens or risks of diagnostic procedures that provide no immediate relief of symptoms. These considerations are uniquely swayed by the values and goals of the patient and must be discussed openly for shared decision making to be effective.

After making a diagnostic plan, the physician and patient must decide together when to transition away from further diagnostic tests and towards treatment. This process might require explicit acknowledgment of acceptable levels of uncertainty. The transition from diagnosis to treatment is not one way, and further considerations (such as new symptoms or the availability of new diagnostic technologies) might warran further diagnostic tests after treatment has started. The diagnostic process might be iterative and have an uncertain timeline or unclear endpoint.

\section{Box 5: Suspected stroke}

An 82 year old woman staying in the hospital after surgery develops new weakness on the right hand side and confusion. A brain CT rules out visible bleeding, and the emergency team want to give the patient alteplase within the three hour window for suspected stroke. The patient's family agrees that, if the patient is having a stroke, they favour treatment with alteplase, but they are concerned that she might not be having a stroke, but rather experiencing side effects from pain drugs. They ask for further testing (such as MRI) to minimise the possibility that the patient receives a high risk treatment for a wrong or highly uncertain diagnosis. These tests would delay giving alteplase, potentially missing the therapeutic window and losing the option of effective treatment.

\section{Discussion}

Decision making in an emergency is fraught with complications. In this example, scientific evidence from treatment trials puts pressure on the healthcare team to give a potentially dangerous treatment as fast as possible; the needs, values, and preferences of the family are sometimes considered secondary or even an impediment to the medical goal. ${ }^{27}$ Yet, these situations, with high uncertainty and high stakes, can benefit from more intensive shared decision making.

We strongly recommend that clinicians develop and implement formalised protocols for shared decision making with patients and their families in emergency situations. This should include establishing roles for clinical personnel, effective communication of risks and constraints, and the use of situation specific decision aids. ${ }^{28}$

\section{Tables}




\begin{tabular}{|c|c|c|}
\hline Function & Physician goals & Skills and techniques \\
\hline Relationship building & $\begin{array}{l}\text { Build mutual trust and rapport with the patient } \\
\text { Discuss roles and responsibilities of all participants (including } \\
\text { family) } \\
\text { Respect autonomy and dignity of patient }\end{array}$ & $\begin{array}{l}\text { Appropriate patient interaction (eg, greeting, eye contact) } \\
\text { Active listening } \\
\text { Body language conveying openness and warmth } \\
\text { Joint agenda setting }\end{array}$ \\
\hline Information exchange & $\begin{array}{l}\text { Understand the key medical and informational needs of the } \\
\text { patient } \\
\text { Appreciate the patient's knowledge and beliefs about their health } \\
\text { Share information in a manner accessible to and understandable } \\
\text { by the patient } \\
\text { Empower patients to better use and evaluate information sources }\end{array}$ & $\begin{array}{l}\text { Ask open ended questions } \\
\text { Active listening } \\
\text { Repeat and summarise } \\
\text { Have patient restate what they understood from the encounter } \\
\text { Provide explanations without jargon } \\
\text { Encourage questioning } \\
\text { Encourage patients to explore other sources of information }\end{array}$ \\
\hline $\begin{array}{l}\text { Responding to patient } \\
\text { emotion }\end{array}$ & $\begin{array}{l}\text { Recognise, understand, and empathise with the patient's } \\
\text { emotions }\end{array}$ & $\begin{array}{l}\text { Legitimate and validate expressed emotions } \\
\text { Demonstrate empathy } \\
\text { Provide help in coping }\end{array}$ \\
\hline Shared decision making & $\begin{array}{l}\text { Elucidate the patient's needs, values, and preferences regarding } \\
\text { care, including desired degree of involvement in decision-making } \\
\text { Deliberate with patient about available options and evidence } \\
\text { Reach mutual agreement about desired course of action }\end{array}$ & $\begin{array}{l}\text { Joint agenda setting } \\
\text { Encourage patient participation in discussion } \\
\text { Active listening } \\
\text { Explore available options, including through the use of decision } \\
\text { ds } \\
\text { Elicit patient goals and values } \\
\text { Accommodate patient preferences }\end{array}$ \\
\hline $\begin{array}{l}\text { Patient empowerment and } \\
\text { self management }\end{array}$ & $\begin{array}{l}\text { Enable patient autonomy, motivation, and self efficacy } \\
\text { Provide guidance, skills, and access to health resources } \\
\text { Advocate for and assist patient in navigating healthcare system }\end{array}$ & $\begin{array}{l}\text { Motivational interviewing } \\
\text { Recommend and instruct patients through necessary steps } \\
\text { Elicit patient goals and values }\end{array}$ \\
\hline
\end{tabular}




\section{Table $2 \mid$ Key differentiating features of shared decision making for diagnosis}

\begin{tabular}{|c|c|c|c|c|}
\hline Attribute & $\begin{array}{l}\text { Shared } \\
\text { decision } \\
\text { making for } \\
\text { treatment }\end{array}$ & $\begin{array}{l}\text { Shared } \\
\text { decision } \\
\text { making for } \\
\text { diagnosis }\end{array}$ & Considerations for the diagnostic encounter & Recommended action \\
\hline \multicolumn{5}{|l|}{ Context } \\
\hline $\begin{array}{l}\text { Patient's primary } \\
\text { concern and goals of } \\
\text { the encounter }\end{array}$ & $\begin{array}{l}\text { How can I get } \\
\text { better? }\end{array}$ & $\begin{array}{l}\text { What is wrong } \\
\text { with me? }\end{array}$ & $\begin{array}{l}\text { Goals of the conversation are focused (largely) } \\
\text { on determining causation, rather than finding } \\
\text { solutions }\end{array}$ & $\begin{array}{l}\text { Emphasise discussion of diagnostic possibilities } \\
\text { and work-up strategy rather than prognosis or } \\
\text { treatment for symptoms or underlying diseases }\end{array}$ \\
\hline $\begin{array}{l}\text { Timeline and process } \\
\text { for decision making }\end{array}$ & $\begin{array}{l}\text { Often } \\
\text { compressed }\end{array}$ & Often iterative & $\begin{array}{l}\text { A correct diagnosis often unfolds over several } \\
\text { encounters over time. Shared decision making is } \\
\text { necessarily iterative, with new information } \\
\text { expected to influence later decision making }\end{array}$ & $\begin{array}{l}\text { Clarify for the patient how you anticipate the } \\
\text { diagnostic process will unfold and over how long. } \\
\text { Define specific objectives for shared decision } \\
\text { making at each encounter and defer further } \\
\text { discussions until later, as appropriate }\end{array}$ \\
\hline $\begin{array}{l}\text { Endpoint of care } \\
\text { process }\end{array}$ & $\begin{array}{l}\text { Most appropriate } \\
\text { treatment choice } \\
\text { for that patient }\end{array}$ & $\begin{array}{l}\text { Diagnostic } \\
\text { uncertainty } \\
\text { resolved } \\
\text { sufficiently for } \\
\text { that patient }\end{array}$ & $\begin{array}{l}\text { Complete diagnostic certainty is rarely achieved. } \\
\text { An endpoint occurs when the search for a specific } \\
\text { diagnosis (or diagnostic confirmation) ends and } \\
\text { the focus shifts to prognosis and treatment }\end{array}$ & $\begin{array}{l}\text { Work with the patient to identify when they are ready } \\
\text { to move away from diagnosis towards symptom or } \\
\text { disease management. This will vary by disease and } \\
\text { by patient preference }\end{array}$ \\
\hline
\end{tabular}

\section{Evidence}

Clarity of the problem Probabilistic Ambiguous space or formulation ${ }^{17}$

The problem formulation is sometimes insufficien to present options or choices, let alone weigh risk-benefit probabilities diagnostic testing to the patient (For example, matter. As appropriate, discuss overdiagnosis ${ }^{1920}$ does a test accurately diagnose disease $X$ ? If so, and incidental findings as potential harms from is treatment $Y$ beneficial in treatment of disease further diagnostic testing $X$ ?). This inference is weaker than a direct inference $^{18}$

Risk of medical error Lower Higher
Diagnostic errors are more common and harmful Discuss uncertainty in diagnosis and the possibility than treatment errors. ${ }^{21}$ Diagnostic decisions are of diagnostic error. Emphasise the patient's role in upstream, so inherently more uncertain and prone prompt identification of misdiagnosis when red flags to error than treatment decisions

\section{Higher}

$$
\begin{aligned}
& \text { The number of possible diseases (and test } \\
& \text { options) is usually very high. Discussing all } \\
& \text { medically reasonable considerations with the } \\
& \text { patient or family is impractical (and potentially } \\
& \text { overwhelming or frightening) }
\end{aligned}
$$

The link between diagnostic strat centred outcomes is usually remote. The strength their symptoms might not lead to a treatment benefit. of evidence to guide choices is often low, requiring Discuss frankly the level of evidence that pursuing a two step inference about the benefit of a diagnosis will lead to improved outcomes that shared goals. This should help guide overall strategy and choosing specific diagnostic tests or consultations

Reserve detailed shared decision making for specific diagnostic test choices that have high stakes and moderate uncertainty (fig $2 \downarrow$ ). Use less time-intensive patient centred care strategies when stakes are low or recommendations clear

$\begin{array}{ll}\text { Proximity to patient } & \text { Greater Lesse } \\ \text { centred outcomes and } & \end{array}$
centred outcomes and base appear or the disease course deviates from the expected path

Patient

\begin{tabular}{lll}
\hline $\begin{array}{l}\text { Psychology of clinical } \\
\text { decision making }\end{array}$ & $\begin{array}{l}\text { Risk-benefit } \\
\text { trade-offs }\end{array}$ & Risk aversion
\end{tabular}

Clinicians often make decisions based on needing Discuss patient values surrounding missed to know the cause first or ruling out the worst case opportunities to diagnose and treat. ${ }^{22}$ Discuss not

\begin{tabular}{|c|c|c|c|c|}
\hline $\begin{array}{l}\text { Burden of intervention } \\
\text { to the patient in relation } \\
\text { to their health outcome }\end{array}$ & Tightly coupled & $\begin{array}{l}\text { Largely } \\
\text { decoupled }\end{array}$ & $\begin{array}{l}\text { Diagnostic testing generally offers no tangible } \\
\text { (direct) benefit to patients, so, in some sense, is } \\
\text { "all risk and no reward"23 }\end{array}$ & $\begin{array}{l}\text { Discuss patient needs, values, and preferences } \\
\text { specifically related to trade-offs between the burden } \\
\text { of testing and resolution of diagnostic uncertainty } \\
\text { or fears }\end{array}$ \\
\hline $\begin{array}{l}\text { Self efficacy and the } \\
\text { role of internet searches } \\
\text { and patient discussion } \\
\text { groups }\end{array}$ & More effective & Less effective & $\begin{array}{l}\text { Diagnostic information on the internet for patients } \\
\text { with common symptoms is often inaccurate or } \\
\text { unreliable, and relevance of other patients' } \\
\text { experiences with the same symptoms is likely } \\
\text { lower than for those with the same disease }\end{array}$ & $\begin{array}{l}\text { Identify specific websites with reliable diagnostic } \\
\text { information or other patient resources (medical } \\
\text { librarians, second consultation services). Discuss } \\
\text { potential risks of using inadequately vetted internet } \\
\text { information or over-inferring diagnoses from } \\
\text { similarities with other patient symptoms }\end{array}$ \\
\hline
\end{tabular}
scenario, without explicitly considering the only the potential harms from testing but also the downsides of further diagnostic testing or patient potential for false positive test results in low risk risk preferences scenarios 


\section{Figures}

\section{Clinical context}

\section{Patient goals}

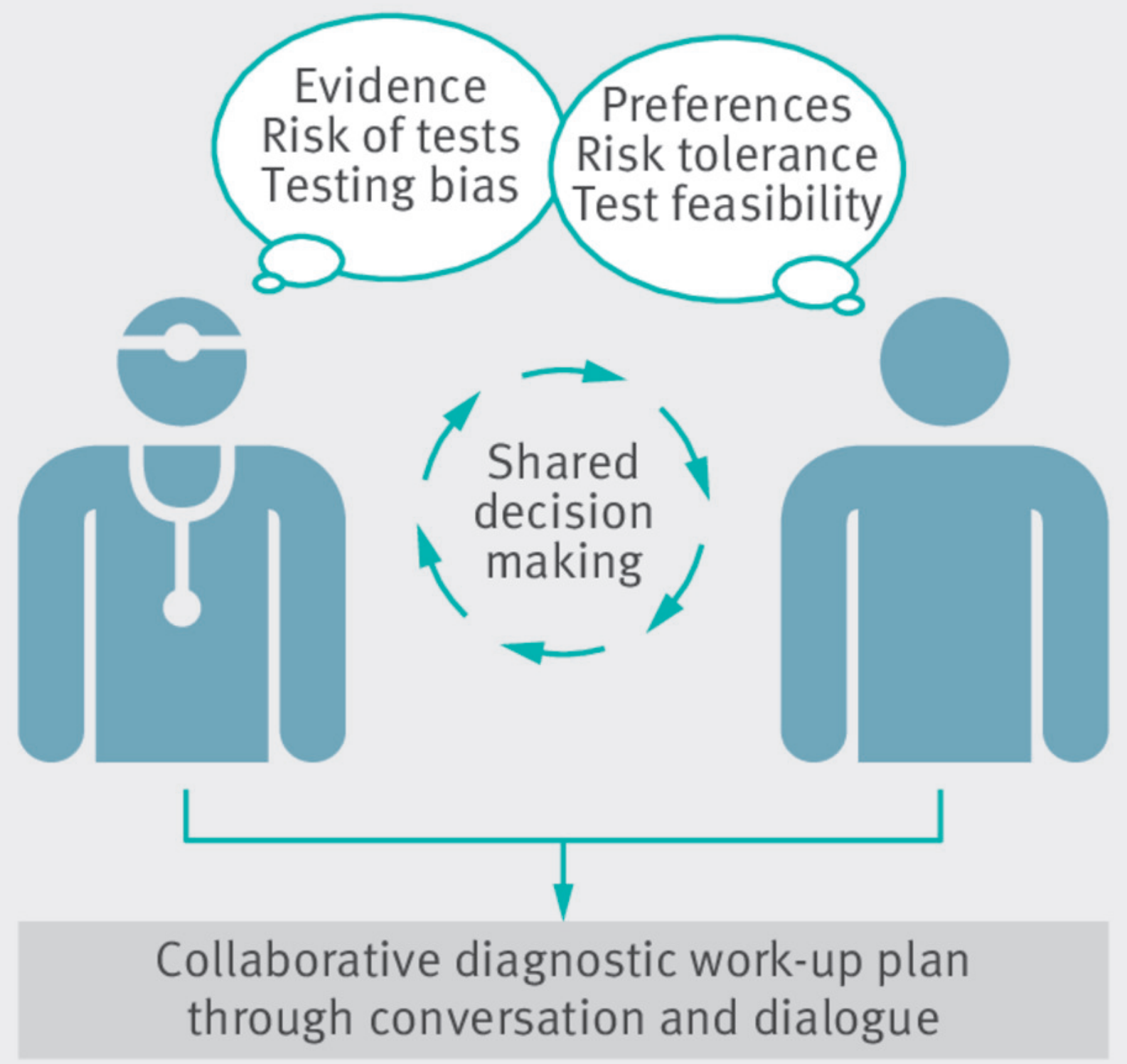

Fig 1 Conceptual model of patient centred diagnosis. Clinical context includes the presenting patient concern, the clinician's role, and the clinical setting. Considering this and the patient's (or family's) overall goals of care, a dialogue between clinician and patient or family should be used to agree on a patient centred diagnostic plan. 


\section{Decision}

stakes

High

Low

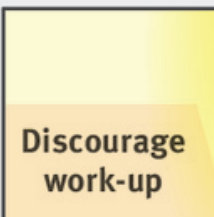

Work-up clearly not beneficial
Evidence

uncertain

\section{Appropriate}

intensity of SDM conversation

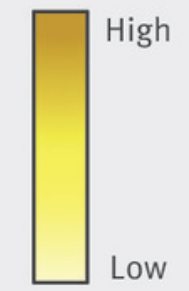

Work-up clearly beneficial

\section{Certainty of evidence in patient specific context}

Fig 2 Framework for adjusting the intensity of shared decision making in patient centred diagnosis based on uncertainty and stakes. When the potential benefit to patients is uncertain, and when diagnostic decisions have high stakes, clinicians should engage in robust, detailed shared decision making with patients. SDM=shared decision making. 